\begin{tabular}{|c|c|c|c|}
\hline DE & \multirow{3}{*}{$\begin{array}{l}\text { DE GRUYTER } \\
\text { OPEN }\end{array}$} & $\begin{array}{l}\text { HUNGARIAN JOURNAL OF } \\
\text { INDUSTRY AND CHEMISTRY }\end{array}$ & $\begin{array}{l}\text { HUUNGARIAN JOURNALI OI } \\
\text { INIDUSTRRY AND CIIIEMISTIRYY }\end{array}$ \\
\hline & & Vol. 44(1) pp. 29-32 (2016) & \\
\hline & & $\begin{array}{l}\text { hjic.mk.uni-pannon.hu } \\
\text { DOI: 10.1515/hjic-2016-0003 }\end{array}$ & {$[1$} \\
\hline
\end{tabular}

\title{
SEPARATION OF PROCESS WASTEWATER WITH EXTRACTIVE HETEROGENEOUS-AZEOTROPIC DISTILLATION
}

\author{
András József Tóth, ${ }^{*}$ Ágnes SZANyI, EnIKö HAAZ, ANd PÉTER Mizsey \\ Department of Chemical and Environmental Process Engineering, Budapest University of \\ Technology and Economics, Múegyetem rkp. 3., Budapest, 1111, HUNGARY
}

\begin{abstract}
The application of vapour-liquid equilibria-based separation alternatives can be extraordinarily complicated for the treatment of process wastewaters containing heterogeneous-azeotropic. Despite dissimilar successfully tested methods for separation, there is possibility to get better distillation method by enabling the separation of more and more specific process wastewater. Extractive heterogeneous-azeotropic distillation (EHAD) is a new advance in treatment of fine chemical wastewater showing special features to cope with the treatment of highly non-ideal mixtures. This method combines the worth of heterogeneous-azeotropic and extractive distillations in one apparatus without addition of any extra materials. The study of the separations of ternary component process wastewater from the fine chemical industry shows both in the modelled and experimental results that EHAD can be successfully applied. The measured and modelled compositions at extreme purities, that is, close to $0 \%$ or $100 \%$, can be different because of the inaccuracies of the modelling. This highlights the paramount importance of the experiments if special extra-fine chemicals with almost no impurities, e.g. of pharmacopoeial quality are to be produced by special distillation technique. This study expands the application of EHAD technique, this new field is the separation of process wastewaters.
\end{abstract}

Keywords: process wastewater, non-ideal mixtures, extractive heterogeneous-azeotropic distillation

\section{Introduction}

The words of Dr. James R. Fair are still true: "Distillation, king in separation, will remain as the workhorse separation device of the process industries. Even though it is old in the art, with a relatively mature technology support base, it attracts research and professional interest. Without question, distillation will sail into the future with clear skies and a strong wind. It will remain the key separation method against which alternate methods must be judged" from Ref. [1]. The above quote clearly explains why distillation should be investigated continuously [2-4].

In our work, the separation of process wastewater is studied. Such mixtures are quite common in pharmaceutical industry, where the treatment of generally azeotropic mixtures and then fine chemical quality should be achieved; while simultaneous, it is challenging to balance the energetic and environmental consequences. Corresponding non-ideal process wastewaters commonly include different varieties of aldehydes, alcohols, ethers and esters in aqueous media. These compounds already foretoken these problems may resurrect during vapuor-liquid equilibria-based treatment. The separation of a water, isopropyl acetate, ethyl acetate and ethanol process wastewater from the pharmaceutical industry [5] has drawn attention to the need for the improvement of the vapour-liquid equilibria-based separation techniques that includes the worth of using different treatment solutions.

A new hybrid treatment alternative, the so-called extractive heterogeneous-azeotropic distillation (EHAD), has been introduced [6-9] that associates the advantages of heterogeneous-azeotropic and extractive distillations (Fig. 1). The heterogeneous-azeotropic opportunity presumes that water component is current in the process wastewater and moreover limited immiscibility may exist. Heteroazeotropic distillation utilizes deviations in volatility and liquid-liquid phase

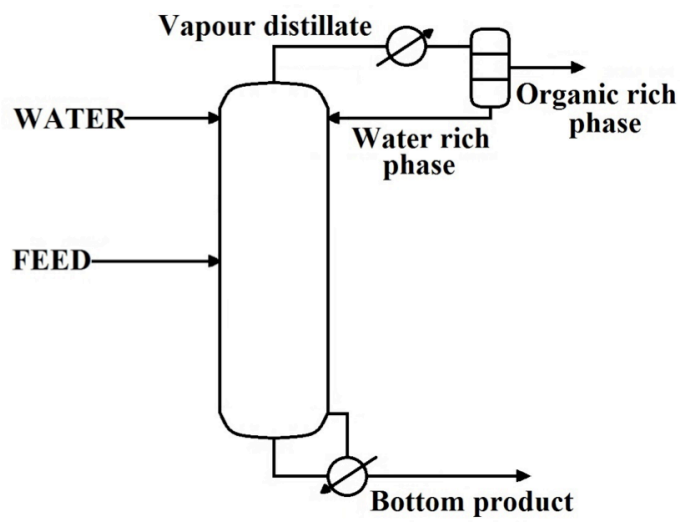

Figure 1. Scheme of the EHAD technique [9]. 
split by connecting a column and phase separator/decanter [10-12].

EHAD differs from heterogeneous-extractive distillation [13] because no new azeotropic mixture is created, videlicet the entrainer is water in the case and it is already current in the process wastewaters to be treated. Furthermore, relative volatility changing and extractive effect of entrainer agent is absolutely utilised and there is no rectifying section in the column [9]. The capability of the extractive heterogeneous-azeotropic distillation can be demonstrated with a case study. This was carried out for a separation method of 9 devices, extractors and distillation columns [14].

If fine purity is required, e.g. in biofuel or pharmacopoeial applications further unit operations might be needed, e.g. rectification again. However, it can be observed that within the range of extreme purities (close to $0 \%$ or $100 \%$ ) the modelling is not reliable enough and the experiments cannot be omitted. The applicability and effectiveness of extractive heterogeneous distillation has been already tested on many different highly non-ideal mixtures with simulations and experiments verifying the accuracy of modelling [8-9]. The strategy clearly shows that EHAD is a forceful method for separation of heterogeneous azeotropic mixtures containing water.

\section{Experimental}

In spite of the clear guidelines for the applicability of EHAD [8], further application areas are going to be investigated. On the other hand, the separation of actual process wastewater should be interpreted explaining the unit operation and identifying new possible application areas.

\subsection{Simulations}

For the sake of our aims, a process wastewater was selected: ethyl acetate (EtAc), methyl alcohol $(\mathrm{MeOH})$ and water $\left(\mathrm{H}_{2} \mathrm{O}\right)$. Flowsheet simulations were achieved with ChemCAD in advance on experiments in order to reduce the necessary number of measurements and to look up promising separation alternatives. Moreover, cooling and heating demands, mass- and waste-flow rates and ideal reflux ratio were also determined. The UNIQUAC equilibrium method is applied [15-18] for the computation of vapour-liquid equilibria of non-ideal mixtures. If binary pairs exist without the availability of UNIQUAC data, the UNIFAC method was applied [19]. Liquid-liquid equilibria were also considered in the form of a vapour-liquid-liquid equilibria (VLLE) model [20]. UNIFAC and UNIQUAC equilibrium models have VLL equilibria options.

The flowsheet of EHAD and intricacies of process wastewater are demonstrated in Fig. 2 computed with ChemCAD. There are one heterogeneous and one homogeneous azeotropes, all in all two binary type [2023].

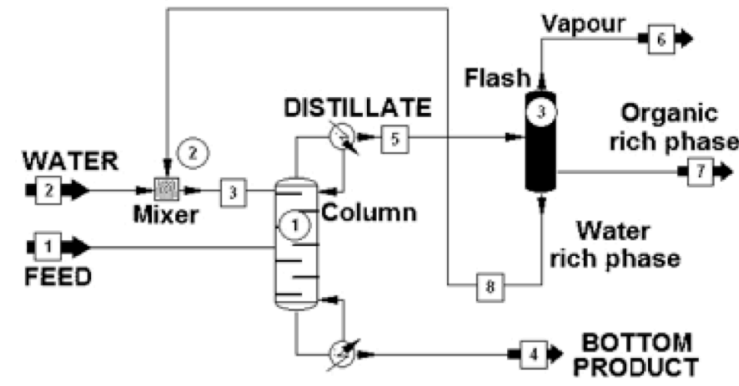

Figure 2. Separation of the process wastewater in flowsheet simulator environment.

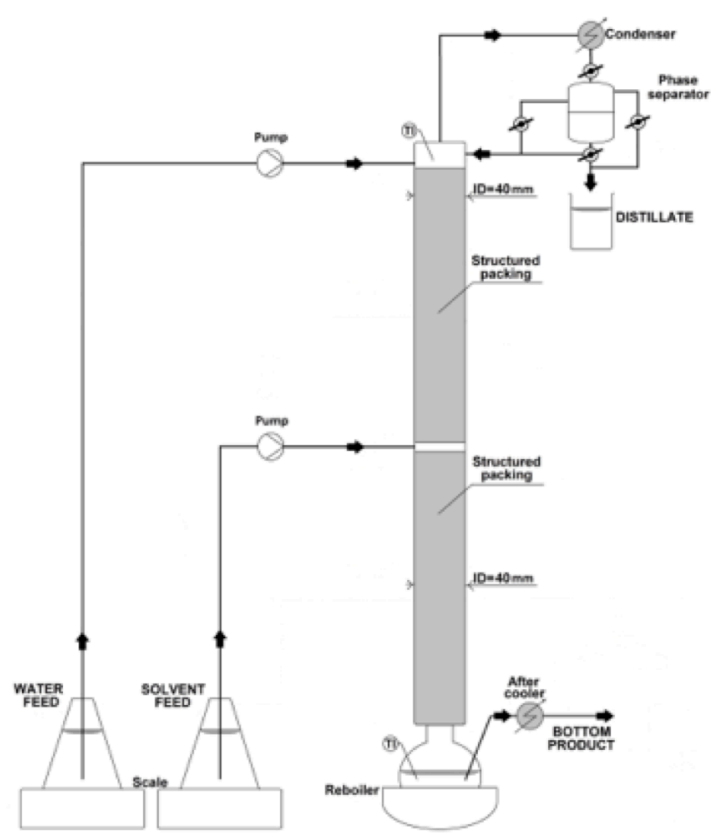

Figure 3. Scheme of EHAD laboratory column.

\subsection{Experiments}

To save material (amount of sample) and experimental time, first of all, comprehensive flowsheet simulations should be implemented. The results of computer simulations foretoken and prepare the measurements. The measurements are achieved on the distillation column of laboratorial size demonstrated in Fig. 3.

The major specifications of the distillation apparatus are succeeding: internal width of $2 \mathrm{~cm}$ structured packing. The theoretical plates of the column are measured with methyl-alcohol - water mixture, that is 10 . The feed $(F)$ is not forewarmed, it is injected on the fifth plate of the apparatus and flow value is kept at $0.06 \mathrm{~kg} \mathrm{~h}^{-1}$. The entrainer is injected on the tenth plate of the tower and flow value is kept at $0.31 \mathrm{~kg} \mathrm{~h}^{-1}$. The apparatus warming is directed with a $0.300 \mathrm{~kW}$ heating crater. The overhead product, after condensation goes to the decanter, or phase separator. The upper phase is measured and the lower phase is pumped as reflux into the apparatus. The concentration of feed, distillate (D), and waste output (W) were measured using a GC-14B type Shimadzu gas chromatographer with CP-SIL-5CB capillary column. 
Table 1. Results of EHAD technique: simulated and measured data (in mass percent)

\begin{tabular}{crrrrr}
\hline & \multirow{2}{*}{ F } & \multicolumn{2}{c}{ simulation } & \multicolumn{2}{c}{ experiment } \\
& & \multicolumn{1}{c}{ D } & \multicolumn{1}{c}{ W } & \multicolumn{1}{c}{ D } & \multicolumn{1}{c}{ W } \\
\hline $\mathrm{H}_{2} \mathrm{O}$ & 4 & 3.6 & 94.7 & 5.3 & 94.6 \\
$\mathrm{MeOH}$ & 26 & 0.1 & 5.2 & 0.2 & 5.4 \\
$\mathrm{EtAc}$ & 70 & 96.3 & 0.1 & 94.5 & b.d.1. \\
\hline
\end{tabular}

\section{Results and Analysis}

We summarise the measured and calculated results in Table 1. The comparison also shows the accuracy of EHAD in the ternary case selected for the given study.

The water addition $\left(x_{\mathrm{F}, \text { water }}\right)$ and the feed content of ternary mixture $\left(x_{\mathrm{F} \text {,solvent }}\right)$ are presented in Fig.4, along with the theoretical waste output $\left(x_{\mathrm{W}}\right)$ and distillate $\left(x_{\mathrm{D}}\right)$ content as well. The two-phase region is found under the dashed curve. Operation of this column is shown by the operating lines.

\subsection{Modelling of High Purity Separation}

The concentrations $0 \%$ and $100 \%$ are two extreme numbers, since these do not exist in practical separation technology. We can approach these numbers with ever more advanced and expensive technologies, but we can never arrive at them. Moreover, the problem of extreme concentrations poses two questions: (i) do we have sophisticated enough analytical techniques to do measurements in such regions, and (ii) can we calculate/model these regions accurately/reliably?

Positive answers are crucial in the case of high purity distillation. Modelling is important since it is used for the reduction of solution space and to find promising alternatives. Modelling can therefore be applied to the preparation and selection of the experiment(s). This philosophy is also applied to high purity rectification problems. In our ternary example we arrive at such an extreme concentration range where our analytics is not capable of following the separation. But the modelling shows some promise here.

Another case studies [6-8] from the fine chemical industry highlights that modelling is not reliable in those regions that are close to the extreme numbers of $0 \%$ and/or $100 \%$. A demonstrative example for such a crucial situation is the production of ethanol of pharmacopoeial purity. The ethanol produced of this purity may contain contaminants only in concentrations of a few ppm. There are alternative processes for the production of such extremely pure ethanol involving rectification. However, modelling alone can be misleading and it might show such solution alternatives that prove to be unacceptable if they are experimentally tested. On the other hand, the modelling results are definitely uncertain within such extreme purity ranges. The modelled results in all likelihood cannot be supported by experiments. These examples show that if rectification-based process alternatives are investigated the experiments yield reliable results, since modelling is

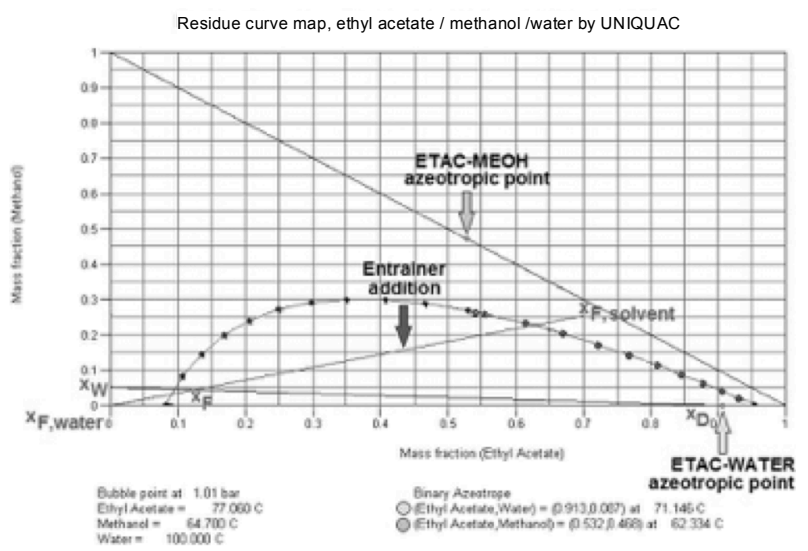

Figure 4. Calculated equilibria and operating lines of EHAD.

unreliable at purities close to the extreme concentration ranges.

\section{Conclusion}

EHAD separation technique improves in the separation of heterogeneous azeotropic mixtures. It opens an alternative solution for distillation specialists. Treatment of difficult process wastewaters can be solved costeffective and easily with application of EHAD.

Comparison of modelling techniques and experiments shows good agreement; however, there might be contradictions among measured and modelled data if high purity products are required. Our results obtained as a solution to fine chemical industrial and other, e.g. pharmacopoeial purity distillation problems show that close to $0 \%$ and/or $100 \%$ concentrations the experiments and modelling can provide unreliable results underlining the paramount importance of experiments and proper analytics.

\section{SYMBOLS}

b.d.1. below detection limit

D distillate

EHAD extractive heterogeneous-azeotropic

distillation

EtAc ethyl acetate

$\mathrm{F} \quad$ feed

$\mathrm{MeOH}$ methyl-alcohol

VLE vapour-liquid equilibrium

VLLE vapour-liquid-liquid equilibria

W waste output

$x_{\mathrm{F}, \text { solvent }} \quad$ feed concentration

$x_{\mathrm{F} \text {,water }} \quad$ entrainer concentration

$x_{\mathrm{D}} \quad$ distillate concentration

$x_{\mathrm{W}} \quad$ waste output concentration 


\section{Acknowledgement}

The research was supported by the OTKA 112699 grant.

\section{REFERENCES}

[1] Kister, H.: Distillation Design (McGraw-Hill Education, New York) 1992

[2] Szabó, L.; Németh, S.; Szeifert, F.: Separation of multicomponent mixtures, Hung. J. Ind. Chem., 2011 39(2), 295-300

[3] Toth, A.J.; Gergely, F.; Mizsey, P.: Physicochemical treatment of pharmaceutical wastewater: distillation and membrane processes, Per. Pol. Chem. Eng., 2011 55(2), 59-67 DOI 10.3311/pp.ch.2011-2.03

[4] Mizsey, P.; Toth, A.J.: Application of the principles of industrial ecology for the treatment of process waste-waters with physicochemical tools, Indust. Ecol., 2012 1(1), 101-125

[5] Mizsey, P.; Szanyi, A.; Raab, A.; Manczinger, J.; Fonyo, Z.: Intensification of a solvent recovery technology through the use of hybrid equipment, Comp. Aided Chem. Eng., 2002 10(1), 121-126 10.1016/S1570-7946(02)80048-7

[6] Szanyi, A.; Mizsey, P.; Fonyo, Z.: Novel hybrid separation processes for solvent recovery based on positioning the extractive heterogeneousazeotropic distillation, Chem. Eng. Proc., 2004 43(3), 327-338 DOI 10.1016/S0255-2701(03)00132-6

[7] Szanyi, A.; Mizsey, P.; Fonyo, Z.: Optimisation of nonideal separation structures based on extractive heterogeneous azeotropic distillation, Ind. Eng. Chem. Res., 2004 43(26), 8269-8274 DOI 10.1021/ie0495751

[8] Szanyi, A.; Mizsey, P.; Fonyo, Z.: Separation of highly non-ideal quaternary mixtures with extractive heterogeneous-azeotropic distillation, Chem. Biochem. Eng. Q., 2005 19(2), 111-121

[9] Szanyi, A.: Separation of non-ideal quaternary mixtures with novel hybrid processes based on extractive heterogeneous-azeotropic distillation (PhD Dissertation, BME, Budapest) 2005

[10]Franke, M.; Gorak, A.; Strube, J.: Design and optimisation of hybrid separation processes, Chem. Eng. Tech., 2004 76(3), 199-210 DOI 10.1002/cite.200406150

[11] Skiborowski, M.; Harwardt, A.; Marquardt, W.: Conceptual design of distillation-based hybrid separation processes, Annu. Rev. Chem. Biomol. Eng., 2013 4(1), 45-68 DOI 10.1146/annurevchembioeng-061010-114129
[12] Skiborowski, M.; Harwardt, A.; Marquardt, W.: Conceptual Design of Azeotropic distillation processes (in Eds.: Gorak, A.; Sorensenm, E.; Distillation: Fundamentals and principles, Academic Press, Aachen, Germany) 2014, Chapter 8, p. 321

[13] Wijesinghe, A.M.J.C.: Development of industrial complexes of special rectification techniques for solvent recovery ( $\mathrm{PhD}$ dissertation, Lomonosov Institute of Fine Chemical Engineering, Moscow) 1985

[14] Raab, A.: Separation of highly non-ideal mixtures for solvent recovery (MSc Thesis, BME, Budapest) 2001

[15] Abrams, D.S.; Prausnitz, J.M.: Statistical thermodynamics of liquid mixtures: A new expression for the excess gibbs energy of partly or completely miscible systems, AIChE J., 1975 21(1), 116-128 DOI 10.1002/aic.690210115

[16]Egner, K.; Gaube, J.; Pfennig, A.: GEQUAC, an excess Gibbs energy model describing associating and non-associating liquid mixtures by a new model concept for functional groups, Fluid Phase Equilib., 1999 158-160, 381-389 DOI 10.1016/S03783812(99)00137-5

[17] Klamt, A.; Krooshof, G.J.P.; Taylor, R.: COSMOSPACE: Alternative to conventional activity-coefficient models, AIChE J., 2002 48(10), 2332-2349 DOI 10.1002/aic.690481023

[18] Wiśniewska-Goclowska, B.; Malanowski, S.X.K.: A new modification of the UNIQUAC equation including temperature dependent parameters, Fluid Phase Equilib., 2001 180(1-2), 103-113 DOI 10.1016/S0378-3812(00)00514-8

[19] Fredenslund, A.; Jones, R.L.; Prausnitz, J.M.: Group-contribution estimation of activity coefficients in non-ideal liquid mixtures, AIChE J., 1975 21(6), 1086-1099 DOI 10.1002/aic.690210607

[20]Akita, K.; Yoshida, Y.: Phase-equilibria in methanol-ethyl acetate-water system, J. Chem. Eng. Data, 1963 8(1), 484-490 DOI 10.1021/je60019a003

[21] Gmehling, J.; Menke, J.; Krafczyk, J.; Fischer, K.: Azeotropic data (Wiley-VCH Verlag GmbH \& Co. KGaA, Weinheim, Germany) 1994

[22] Gmehling, J.; Onken, U.; Rarey-Nies, J. R.: Vaporliquid equilibrium data collection (Dechema, Virginia, USA) 1978

[23] Marsden, C.: Solvents And Allied Substances Manual With Solubility Chart (Cleaver-Hume and Elsevier, London) 1954 